\title{
Coverillustration
}

\section{Cure for a headache}

S ometimes it seems that you are simply banging your head against a brick wall, as the frustrations of contemporary life seem to conspire against you. For us, life's headaches are common enough, but what if you spent your life battering your head against a wall-intentionally? How would you avoid headaches, concussions, "shaken baby" syndrome, or even retinal detachments?

The pileated woodpecker (Dryocopus pileatus) illustrated on this month's cover is North America's largest woodpecker, with only the ivory billed and imperial woodpecker of Mexico, if either species is not extinct, being larger. Woodpeckers hammer their lives away for feeding, nest construction, and drumming. A canopy dweller with a voracious appetite, $D$ pileatus depends on a diet rich in protein, with ants the preferred food. Various berries and wild fruits may represent a mainstay in the autumn and winter months. The hollowed nest cavity is extraordinary in size, up to 8 inches in diameter and 2 feet deep. The drumming is species specific and may be used for communication or territorial display, but is not related to feeding. As a result of these activities, D pileatus may strike the hard woody surface of a tree at a rate of up to 20 times a second (not a misprint) and up to 12000 times a day with staggering deceleration forces of as high as $1200 \mathrm{~g}$ with each impact. That is equivalent to striking a wall at 16 miles an hour-face first-each time.

This crow-sized, furtive, and wary woodpecker, as well as most of the approximately 300 known woodpecker species, has evolved several unique mechanisms to prevent brain damage, retinal haemorrhages, and retinal detachment.

The bird's name comes from Linnaeus (1758) who chose the name pileatus, which is Latin for "crested." The bird eventually became known as the pileated woodpecker, although it was called other, more picturesque, names such as log-cock, stump-breaker, and laughing woodpecker.

To equip the bird for its ecological niche, evolution has provided the woodpecker with a thick bony skull with relatively spongy bone, especially at the occiput, and cartilage at the base of the mandible to partially cushion the incessant blows. Inside the skull, there is

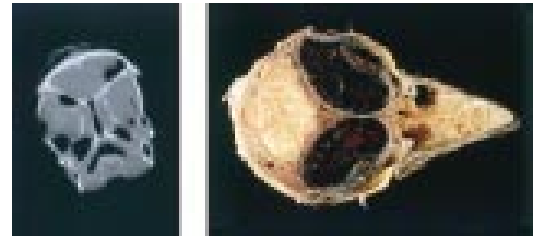

Left: Computed tomograph (CT) scan of pileated woodpecker head. This sagitta section is at the approximate mid-point of the skull. The hyoid bone can be seen as small white opacities just inferior to the eyes as illustrated with the black arrow. (Scan by Erik R Wisner, DVM, School of Veterinary Medicine, University of California Davis.) Right: Woodpecker skull cut in A-P direction illustrates the dense, yet spongy, bone and the narrow subarachnoid space. Note the large eyes compared with the brain.

(Photograph by IRS.)

almost no cerebrospinal fluid in a very small subarachnoid space. The mandibles are attached to the skull by powerful muscles that contract a millisecond before strike, creating a tight, but cushioned structure at the moment of impact and distributing the force of the impact to the base and posterior aspects of the skull, thus bypassing the brain (May et al, Lancet 1976;1:454-5). The neurological mechanisms must be superb since these birds strike in a perfect perpendicular stroke to eliminate the torsional shear force that would otherwise tear the meninges or cause concussions (May et al, Arch Neurol 1979;36:370-3). Although not studied, this mechanism probably also protects against intraretinal haemorrhages and retinal detachment. Additionally, the woodpecker is protected, at least to some extent, by its size. Its brain is relatively small, resulting in a small ratio of brain weight to brain surface area. Any impact force would be spread out over a relatively large area making its brain somewhat more resistant to concussion than a human's brain Nevertheless, the woodpecker will use the leverage of its entire body weight to increase the force of impact of its bill, and it becomes a full body hammer.

The same high speed photography that has documented its strike mechanism has revealed that in that millisecond before strike the thickened nictitans closes over the eye. This would protect the eye from flying debris and chips, but would also act as a "seat belt" to restrain the eyes from quite literally "popping out of its head." Woodpeckers enjoy a cushioned choroid with an as yet unknown mucopolysaccharide filling the interstices. The pecten probably also has a role in maintaining an effective cushion as the pecten can fill with blood to briefly elevate intraocular pressure thus maintaining firm pressure on the lens and retina to prevent damage.

The woodpecker has other unique adaptations that deserve recognition and may contribute to the protection from intracranial injuries. The tongue is most unusual as it originates on the dorsum of the maxilla, passes through the right nostril, between the eyes, divides into two, arches over the superior portion of the skull and around the occiput passing on either side of the neck, coming forward through the lower mandible, and uniting into a single tongue in the oropharyngeal cavity. The muscles encase the bony hyoid throughout this muscular course into the oropharynx and are additionally secured in the floor of the mouth creating an apparatus that allows for extraordinary protrusion of the tongue of up to 4 inches beyond the tip of the bill! These musculotendinous bands create a curious sling-like structure that probably functions as an isometric shock absorber if contracted before each strike. This sling would also serve to distribute the potential shearing forces (May et al, Lancet 1976;1:454-5). Such length is useful for penetrating insect nests beneath the bark of trees. The sharp tongue (literally) is coated with sticky saliva for smaller insects such as ants and has backward pointing barbs that are useful in impaling larger insects and grubs. For added emphasis, the tongue is equipped with excellent tactile abilities to allow for recognition of smaller insects, such as ants. The chisel tipped mandibles are constructed of individual fused plates of keratin called rhamphotheca, and the longitudinal trabeculae are reinforced with calcium.

So, when you complain about your headache, think of the industrious woodpecker.

\section{Ivan R Schwab}

University of California, Davis, Department of Ophthalmology, 4860 " $Y$ " Street, Suite 2400, Sacramento, CA 95817, USA: irschwab@ucdavis.edu

Cover photograph by F Truslow@VIREO. 